\title{
An Exploration of Schema Theory in Intensive Reading
}

\author{
Yanxia shen \\ School of Foreign Languages \\ HeBei University of Science and Technology \\ 186 East YuHua Road, ShiJiaZhuang \\ Hebei 050018, China \\ E-mail: shenyanxia21@hotmail.com
}

\begin{abstract}
Considering the difficulties in understanding the global meaning of texts, this paper intends to give some suggestions on how to help students reach a deeper understanding of texts in intensive reading classroom within the framework of schema theory. The purpose of this paper is expressed in three ways. The first is to give a brief overview of some of the literature that deals with schema theory as part of a reader centered psycholinguistic processing model for both native and non-native readers. The second goal is to show how familiarity with the subject matter in terms of schema theory affects L2 understanding about the text. The third one is to discuss the implications of schema theory in L2. The conclusion can be made that texts become easier to understand when the teacher enhances the students' prior knowledge. Background knowledge is a bridge connecting existing knowledge in mind with the new text. .
\end{abstract}

Keywords: Global meaning, Schema Theory, Intensive Reading

\section{Introduction:}

In traditional English teaching, new words and grammatical rules were regarded as the core of English learning. The students were only supposed to understand the words or sentence meaning rather than the overall meaning of a text. With the development of the society and the requirement of modern English teaching and learning, the general understanding of texts is becoming more important in the process of English teaching. What has affected their reading ability? Why do most readers have difficulties? How can language teachers help the students to improve their reading ability? The general knowledge of the world is of prime importance for the readers to have better understanding in the reading process. This paper mainly discusses these two aspects of reading in terms of the framework of schema theory and its application to the teaching of English intensive reading.

\section{Literature Reviews}

According to Goodman(1971), reading is a "psycholinguistic guessing game." He thinks that in the reading process, the "reader reconstruct, as best as he can, a message which has been encoded by writer as a graphic display". In 1979, Coady elaborated in this basic psycholinguistic model for reading and suggested a model in which the reader' $\mathrm{s}$ background knowledge interacts with conceptual abilities and process strategies to produce comprehension. Since then, a top-down approach has been used in second language reading. In the reading process, the reader is an active participant, making predictions and processing information. Background knowledge plays a significant role in promoting the reader to get information in the process. The role of background knowledge in language comprehension has been formalized as the Schema theory.

According to the Schema theory, a text only provides directions for listeners or readers as how they should retrieve or construct meaning of their own, namely acquired knowledge. This previously acquired knowledge is called the reader' $\mathrm{s}$ background knowledge. For the previously acquired knowledge structures are called Schema Theory.

An important aspect of cognitive science, Schema Theory is a theory of how knowledge is acquired, processed, and retrieved. Schema is the technical term used by cognitive scientists to describe how people process, organize, and store information in their heads. Schemas, or schemata, are seen as cognitive constructs by which we organize information in our long-term memory (Widdowson, 1983). They "reflect the experiences, conceptual understanding, attitudes, values, skills, and strategies ... [we] bring to a text situation"(Vacca \& Vacca, 1999: 15). Schemata, therefore, have been called "the building blocks of cognition" (Rumelhart, 1982) because they represent elaborate networks of information that people use to make sense of new stimuli, events, and situations. 
Schema theory is based on the belief that "every act of comprehension involves one's knowledge of the world" (Anderson et al. 1977, cited in Carrell \& Eisterhold, 1983: 73). Similarly, and more elaborately, Smith, (1994: 8) states that everything we know and believe is organized in a theory of what the world is like, a theory that is the basis of all our perceptions and understanding of the world, the root of all learning, the source of hopes and fears, motive and expectancies, reasoning and creativity. And this theory is all we have. If we make sense of the world at all, it is by interpreting our interactions with the world in the light of our theory. The theory is our shield against bewilderment.

The Schema theory thinks that comprehending a text is an interactive process between the reader' $\mathrm{s}$ background knowledge and the text. Comprehension of the text requires the ability to relate the textual material to one' $\mathrm{s}$ own knowledge. Comprehending words, sentences, and entire texts involves more than just relying on one' s linguistic knowledge. As Anderson (1977) points out, "every act of comprehension involves one' s knowledge of the world as well. Obviously, the more knowledge of the world one has, the better comprehension he gents about the text.

According to the Schema theory, the process of interpretation is guided by the principle that input is mapped against some existing schema and that all aspects of that schema must be compatible with the input information. This principle results in two basic models of information processing. Which are called bottom-up and top-down processing. Bottom-up processing is evoked by the incoming data and is also called date driven, because the data enters the system through the best-fitting, bottom level schemata. Top-down processing takes place as the system makes general predictions based on higher level, general schema, which means background knowledge in reading comprehension. In the Schema theory, skill in reading depends on the efficient interaction between linguistic knowledge and knowledge of the world. Readers understand what they read because they are able to take the stimulus beyond its graphic representation and assign its membership to an appropriate group of concepts already stored in the memories. During the reading process, the reader brings information, knowledge, emotion, experience, and culture to the printed word to make decisions about what something" means".

From the schema theory, it is clear that meaning is not fully presented in a text passively waiting to be decoded by the reader. Meaning is reconstructed or created the reading process through the interaction of text and the reader's background knowledge. So what the teacher should do is to teach the students to link their prior knowledge with the text. By doing this the students can better understand the global meaning of the text.

\section{Methods used in Language Teaching}

\subsection{Exploring Background Knowledge}

Taking the theories reviewed above into consideration, one can understand the importance of the role of prior knowledge in second language reading. The following methods may help the students to enlarge the background knowledge and link the prior knowledge to the text so as to direct them into a much deeper understanding of the text.

Pre-reading activities are some classroom activities related to the text before reading, including webbing, brainstorming, strip sentences, songs, role-play, predicting, initial discussion, guessing the title or the ending, word list of prediction, opinion poll and charts, etc. These activities don' $t$ tell the students anything that they can find out themselves by reading the text. Instead, they make the students want to read the text and help them to relate the text to his own experience, interests and aims. Take initial discussion for example, before explaining the text, the students are asked to discuss some topics related to the text in groups. By doing this, the students are guided into a situation where they may use language, which has not yet been taught. So they have to search for circumlocutions, to search the memory for items learnt long ago to express their ideas. This initial discussion will be an exchange of ideas. Focus will be on the meaning and students will take the initiative role of the class. In addition, this will allow a variety of interpretations of the passage because at this stage, the students have not been confined by the correct answer of the teacher' s. They have more freedom to extend their fellow students' idea to develop their own thinking. Therefore, the students can get a chance to link the knowledge they have learnt before the text they are going to learn. And it also increases their motivation and gives them a more positive attitude towards the new text. The students will become eager to see what happens next and naturally bring their prior knowledge to the text. The usefulness of pre reading activities can be concluded in Brown' s words (1993) "before you read, spend some time introducing a topic, encouraging skimming, scanning and activating schemata. Students can bring the best of their knowledge and skills to a text when they have been given a chance to "ease' into the passage".

\subsection{Enriching the Students' Background Information}

According to the schema theory, a text only provides directions for the readers as to how they should construct meaning from their background knowledge. Comprehending a text is an interactive process between the reader's background knowledge and the text, and efficient comprehension requires the ability to relate the textual material to one' s own knowledge. If the students haven' t enough relevant knowledge and comprehensible culture-based input to the text, they will fail to read and understand even the simplified text of a major field. As we know, language is the carrier of culture, but there are almost no such courses as Western Culture, Customs and Habits offered in most Chinese 
universities for non-English majors. One possible way to help the students to a much deeper understanding is to enrich their background information. That is to say, teachers should select or develop appropriate materials for students to read in order to help them minimize cultural misunderstanding and interference and to maximize comprehension of reading materials. For instance, to introduce some common sense about western customs, habits, educational systems and so on. Present short and varied materials, which should never be so challenging, neither too difficult nor too simple, but always meaningful and rewarding and students can work out them through efforts. In this way students' prior knowledge is gradually built up, which will eventually facilitate reading in general. In the process of this kind of reading, students may feel frustrated now and then, but they can work through these reading materials successfully because of their variety and briefness. Students will find them interesting and exciting, because the repeated vocabulary of a particular topic or the particular style of a writer is presented to him continuously. According to the Schema Theory, when the schemata are repeatedly activated and further enlarged and refined and accommodated, one' s reading comprehension will be greatly improved.

\subsection{Analyzing the Structure of Texts}

Ellis (1994) states that conscious rising directed at specific structure can result in subsequent noticing of these structures in input. And this noticing may help retention of the structures. Windonson(1983) also states that effective comprehension depends on the reader' $\mathrm{s}$ ability to relate what is being read to a familiar pattern or schema. So different text patterns are gradually introduced to the students and taught them some features of different kinds of texts in order to develop competence in text patterns. A well-written text is often put in a logical pattern. Recognizing the pattern will enable students to better understand what they are reading. Therefore, the students are taught consciously how to organize and use their existing schemata in relation to a specific text and its content.

When students are taught the structure of text, they are helped to find some word clues because of the signals of certain patterns of texts, which may help students know when a certain pattern is being used. There are several groups of signal words and phrases such as "first"."second". "then" ."after" and" finally" signal an order to sequence of events, and words such as "how ever "."but". "otherwise" and "yet" signal the change of thoughts, which indicate a comparison pattern. Besides signal words, students can use other clues such as the title of a text, and topic sentence of a paragraph. For example, the title of a text usually gives the hint of what the author writes about, so the reader can predict the content and overall structure of a text. A topic sentence is one that introduces the central idea of a paragraph.

It is a very common practice to begin a paragraph with the topic sentence and then develop and explain it by giving supporting details and specific examples. By teaching the students to find the topic sentences of paragraphs and analyze the structure of the text, they can identify the central idea of a text easily. In addition to the above approaches, the students can distinguish facts from opinions in order to develop their reading comprehension skills.

\section{Application of Schema theory in the process of text teaching}

In the process of text teaching, the students will be directed to know how many sections the texts will be divided into. For instance, materials related to the text will be listed as follows:

1) About the author

2) About the background

3) About the words

4) About the explanation of the text

5) About the structure of the text

6) About the phrases in the text and exercises

7) About the useful sentences for writing

8) The deep meaning of the text

9) Writing

10) The implication of the text in English language teaching

These items are not taught separately, but related. The students, as any item is required to learn, are supposed to do something before text learning. In the process of Pre-reading, the first three items are required to learn about. The students will have to know some information about the author, his life, his living background, and the related information about the text. These activities mainly take place among the students or sometimes between the teacher and the students.

In the process of while-reading, which is the main process of learning the text. The teacher will explain the text basing on the global meaning of the text. After the explanation of the text, the students will be required to have a summary about the text and give the structure of the text. These actives mainly take place between the students and the students or 
the students and the teacher. The structure of the text can train students to think orderly and logically. The teaching activities are students-centered. Everything taught in the classroom is related to the pre-reading process, which the students have learned before the text. That is, background knowledge (schema theory) plays an important role in text learning.

In the last step, that is post-reading process, the students will learn useful phrases in the text, which are the basic unit in writing. The students will write an article or an essay, using the phrases learned in the text. If necessary, the students are required to recite some paragraphs, which will be helpful in writing. Furthermore, the students will be required to express their ideas about the text, which will be useful in improving their speaking ability. In this way the students can be found how much they have understood the text (input) and how much they can speak out. (output).

It can said that in the fist step (pre-reading is self-learning, the students are doing input. In the second step (while-reading) is still input process, but the difference is while-reading is basing on the first step. It is a further understanding process in text learning. In the process of post-reading, it is completely a output process, which is shown in two ways, speaking and writing. In intensive reading, texts can be taught in this model.

\section{Conclusion}

As Hudson(1982)said the significance of background knowledge in the interpretation of texts by showing that schemata can overside language proficiency as a factor in comprehension. The above training approaches are certainly helpful to enhance the students' prior knowledge and guide them to link their existing knowledge to the new world so as to reach a global understanding of the text. Background knowledge is also a bridge connecting input and output. It helps students to receive the new easily, and also promotes students to produce their thinking, which improve their comprehensive ability.

\section{References}

Anderson R C R E Reynolds \& D L Schallert. (1977). et al.Frameworks for comprehending discourse. American Edu-cational Research Journal, 14(4):369.

Clark Mark A, Silberstein \& Sandra. (1977) . Toward a realization of psycholinguistic principles for the ESL readingclass. Language learning, 27(1):136-137.

Coady J. (1979). A psycholinguistic model of the ESL reader in Reading in a second language. Rowley, mass: New-bu.5-12.

Ellis Gail, Sinclair \& Barbara. (1994). Learning to leam English:A Course in learner training.. Cambridge: Cam-bridge University Press, 273.

Goodman K. S. (1971). Psycholinguistic universals in the reading process.In The psychology of second language learning. Cambridge: Cambridge University Press. 135.

H. Douglas Brown. (1994). Teaching by principles. New Jersey: Prentice Hall Regents, Simon and Shuster Compa-ny. 300-301.

Hudson T. (1982). The effects of induced schemata on the"short circuit"in L2 reading. Language reading, 32 (1):1-31.

Rumelhart Schemata. (1980). The building blocks of cognition in The oretical issues in reading comprehension. Hillsdale:N,J.Erlbaum.33-58.

Widdowson H. G. (1983). Learning purpose and language use. London: Oxford University Press. 287. 